\title{
Tracing the unreliability and recognizing the weak parts of shipboard power system
}

\author{
Dan MEl 1,2,a , Gongbao WANG ${ }^{1, b}$, Zhihao YE ${ }^{2, c}$ \\ ${ }^{1}$ College of Sciences, Naval University of Engineering, Wuhan 430033, China \\ ${ }^{2}$ National Key Laboratory for Vessel Integrated Power System Technology, Naval University of \\ Engineering, Wuhan 430033, China \\ aemail: may1380@163.com, bemail:wanggongbao@126.com, cemail: yxyx928@126.com
}

Keywords: unreliability contributions, tracing principle, weak parts, shipboard power system.

\begin{abstract}
Weak part analysis of a system is a key element in a system reliability quantification process. It enables the weakest areas of a system to be recognized and assists in directing remedial measures for improving the system reliability. This paper proposes an unreliability tracing technique for a ring shipboard distribution system. The case studies indicate that the developed technique can distribute the system unreliability indices to components reasonably, and can therefore be used to recognize the weak parts of a shipboard power system.
\end{abstract}

\section{Introduction}

The complexity in the structure of the shipboard power system is increasing due to a continuous increase in the number of components. Each component in the shipboard power system has a different impact on the system unreliability. Considerable studies have been done in the development of reliability modeling techniques and algorithms and risk analysis [1-9], but there has been relatively little research on the unreliability tracing (UT) technique. References [10-11] present a quantitative assessment of the contribution of a selected component to the system unreliability and it will be useful to identify the weak parts of the system. This information can provide the power system planners and operators with useful information in reliability assessment.

\section{Reliability tracing based on the minimal cut set}

Minimal cut set method

The minimal cut set (MCS) is a set of system components, which when failed, causes failure of the system but any one component of the set has not failed, does not cause system failure [1-3]. These MCSs are considered to be in series, but the components in the MCS are considered to be in parallel.

The unreliability $Q_{s}$ of a system is given by

$$
Q_{s}=P\left(M_{1} \mathrm{U} M_{2} \mathrm{U} \ldots . \mathrm{U} M_{N}\right)
$$

Where the ith MCS is designated as $M_{i}$, its occurrence probability is designated as $P\left(M_{i}\right)$, and $N$ is the number of MCS.

According to the addition formulas, $Q_{s}$ of a system can be calculated as follows:

$$
\begin{aligned}
Q_{s} & =\sum_{i=1}^{N} P\left(M_{i}\right)-\sum_{i>j} P\left(M_{i} \mathrm{I} \quad M_{j}\right) \\
& +\cdots+(-1)^{K-1} \sum_{i_{1}>i_{2}>\cdots i_{K}} P\left(M_{i_{1}} \mathrm{I} \cdots \mathrm{I} M_{i_{K}}\right) \\
& +\cdots+(-1)^{N-1} P\left(M_{1} \mathrm{I} \cdots \mathrm{I} M_{N}\right)
\end{aligned}
$$

It is assumed that the unreliability of the ith component $C_{i}$ is $P_{i} \quad(i=1,2, \ldots, N)$, and MCS $\left\{M_{i_{1}}, M_{i_{2}}, \cdots, M_{i_{K}}\right\}=\left\{C_{1}, C_{2}, \cdots, C_{M}\right\}$. If it is assumed that all components are independent, 


$$
P\left(M_{i_{1}} \mathrm{I} \cdots \mathrm{I} \quad M_{i_{K}}\right)=\prod_{i=1}^{M} P\left(C_{i}\right)
$$

The unreliability of a network $Q_{s}$ can be calculated based on (2) and (3).

\section{Tracing principle}

The purpose of using the unreliability tracing technique is to determine the allocation proportion of these failure components to the unreliability of the system. This paper presents the following two UT Principles:

(1)FCSP: Only the failed components take on the responsibility for the system unreliability. In other words, the healthy components are not considered in the unreliability tracing.

(2)PSP: The reliability indices are proportionally distributed among all the system components according to the proportional sharing principle.

Assume a system consisting of $N$ components $C_{i}(i=1,2, \ldots, N)$. Let $x_{i}(i=1,2, \ldots, N)$ represent the performance parameters, $\varphi\left(x_{1}, x_{2}, \ldots, x_{N}\right)$ represent a reliability index of a state, such as LOLP, FLOL, and EENS, which is the function of $x_{1}, x_{2}, \ldots, x_{N}$.

As an example, consider a failure state resulting from the outage of $C_{1}$ and $C_{2}$. It is assumed that $\varphi\left(x_{1}, x_{2}, \ldots, x_{N}\right)$ can be divided into three separate terms. The first term $\varphi_{1}\left(x_{1}\right)$ is only related to $C_{1}$, the second term $\varphi_{2}\left(x_{2}\right)$ is only related to $C_{2}$ and the third term $\gamma\left(x_{3}, x_{4}, \ldots, x_{N}\right)$ is related to other components. Thus

$$
\varphi\left(x_{1}, x_{2}, \ldots, x_{N}\right)=\varphi_{1}\left(x_{1}\right) \varphi_{2}\left(x_{2}\right) \gamma\left(x_{3}, x_{4}, \ldots, x_{N}\right)
$$

Only the failed components $C_{1}$ and $C_{2}$ are responsible for the particular system failure state. The terms $\varphi(k \rightarrow 1)$ and $\varphi(k \rightarrow 2)$ are used to describe the unreliability obligation of components $C_{1}$ and $C_{2}$. According to the PSP, the two terms can be obtained from equations (5) and (6).

$$
\begin{aligned}
\varphi(k \rightarrow 1) & =\frac{\varphi_{1}\left(x_{1}\right)}{\varphi_{1}\left(x_{1}\right)+\varphi_{2}\left(x_{2}\right)} \varphi\left(x_{1}, x_{2}, \ldots, x_{N}\right) \\
\varphi(k \rightarrow 2) & =\frac{\varphi_{2}\left(x_{2}\right)}{\varphi_{1}\left(x_{1}\right)+\varphi_{2}\left(x_{2}\right)} \varphi\left(x_{1}, x_{2}, \ldots, x_{N}\right)
\end{aligned}
$$

It can be seen from equations (5) and (6) that this principle has two features:

(1) Symmetry. This means $C_{1}$ or $C_{2}$ is only a symbol and it can be used to represent any component.

(2) Identity. This means that

$$
\varphi(k \rightarrow 1)+\varphi(k \rightarrow 2) \equiv \varphi\left(x_{1}, x_{2}, \ldots, x_{N}\right)
$$

\section{Indices of reliability tracing}

The basic reliability indices are the loss of load probability (LOLP), loss of load frequency(LOLF), expected energy not supplied(EENS) and so on.

Based on the reliability evaluation principle, the system index LOLP for a power system is given by [2]:

$$
L O L P=\sum_{k \in \Lambda} p(k)
$$

Where $\Lambda$ is the set of all system failure states with loss of load in a given time interval, $p(k)$ is the probability of a system failure state $k$.

The tracing result of the reliability index LOLP for component $C_{i}$ with all system states is given by:

$$
L O L P_{i}=\sum_{k \in \Lambda} p(k \rightarrow i)
$$

Where $p(k \rightarrow i)$ is the probability distribution results of component $C_{i}$.

The UT index LOLP\% for individual components is defined as follows: 


$$
L O L P_{i} \%=\frac{L O L P_{i}}{L O L P}
$$

The proposed index LOLP\% indicates the percentage contribution of component $C_{i}$ to the system UT index. In other words, a high the magnitude of LOLP\% for a component indicates high impact of the component on the overall system unreliability.

\section{Reliability analysis of shipboard distribution systems}

\section{Topological network model of shipboard distribution systems}

Generally speaking, the network structures of shipboard power system mainly include three types as follows: radial network structure; ring network structure; zonal network structure. The ring shaped shipboard distribution system is shown in Figure 1. The topology model of this ring shaped shipboard distribution network is shown in Figure 2.

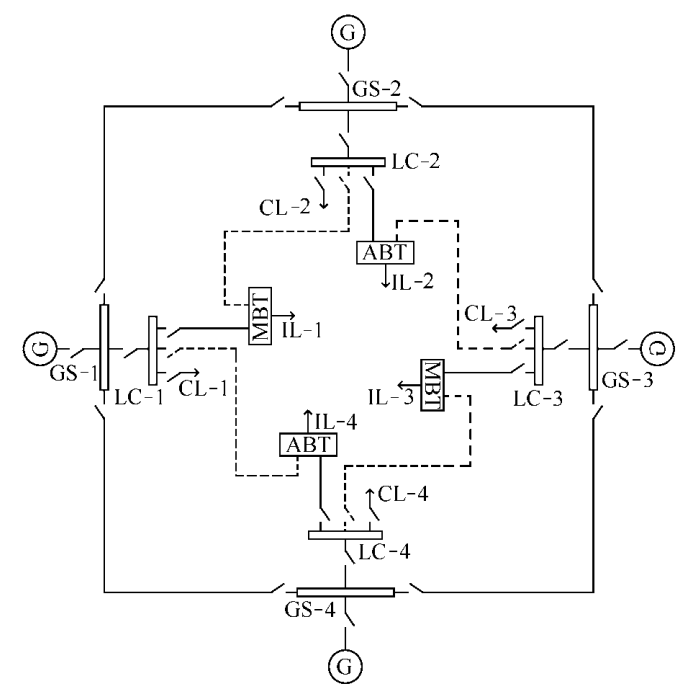

Fig.1.Sketch map of ring shipboard distribution system

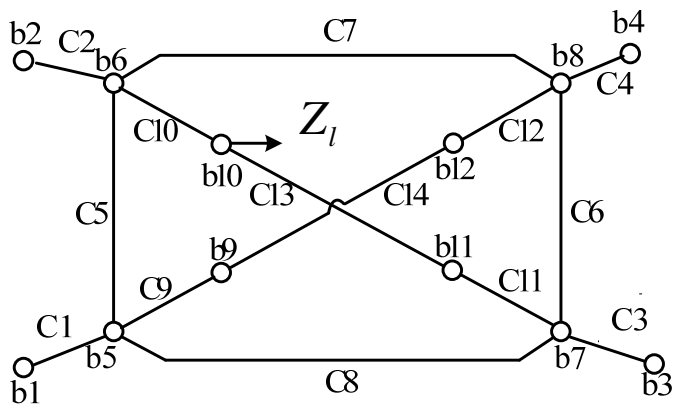

Fig.2.complex network model of ring shipboard distribution system

The elements of shipboard distribution system are generators(G), generator switchboards(GS), load centre(LC), common load(CL)and important load(IL). All of the elements are modeled as nodes and the connecting relationships between nodes are modeled as edges. Nodes $b 1-b 4$ represent generator, $b 5-b 8$ represent generator switchboards, $b 9-b 12$ represent load centre switchboards.

\section{Analysis of reliability indices}

The relevant reliability indices of components are shown in Table1.

Table1. reliability indices of components

\begin{tabular}{|c|c|c|c|c|}
\hline Device name & $\begin{array}{c}\text { Failure rate } \\
\text { (occurrences/year) }\end{array}$ & $\begin{array}{c}\text { Repair time } \\
\text { (hours/ } \\
\text { occurrence) }\end{array}$ & $\begin{array}{c}\text { Planned maintenance } \\
\text { rate (occurrences } \\
\text { /year) }\end{array}$ & $\begin{array}{c}\text { Planned maintenance } \\
\text { time (hours/ } \\
\text { occurrence) }\end{array}$ \\
\hline generator & 0.1 & 120 & 1 & 50 \\
\hline converter & 0.002 & 40 & 0.5 & 20 \\
\hline $\begin{array}{c}\text { Generator } \\
\text { breaker }\end{array}$ & 0.004 & 12 & 0.2 & 30 \\
\hline $\begin{array}{c}\text { Generator } \\
\text { switchboard }\end{array}$ & 0.001 & 30 & 0.5 & 40 \\
\hline lines & 0.001 & 20 & 0.5 & 5 \\
\hline
\end{tabular}

Edges $c 1-c 4$ represent the series of generator breaker and main bus-bar, edges $c 5-c 6$ represent the series of isolated switch and main bus-bar, edges $c 7-c 8$ represent the series of communication circuit breaker and main bus-bar, edges $c 9-c 12$ represent the series of converter, breaker and main bus-bar, edges $c 13-c 14$ represent the lines. 
In order to calculate the LOLP index of the edges, this paper calculate failure rate $\lambda$, repair time $r$, planned maintenance rate $\mu$ and planned maintenance time $t$ based on series system model. For a series system composed of components, the number of the components is $N$. Based on Markov process theory, the equivalent indices of components are given by:

$$
\begin{array}{r}
\lambda=\sum_{i=1}^{N} \lambda_{i} \\
r=\frac{\sum_{i=1}^{N} \lambda_{i} r_{i}}{\sum_{i=1}^{N} \lambda_{i}} \\
\mu=\sum_{i=1}^{N} \mu_{i} \\
t=\frac{\sum_{i=1}^{N} \mu_{i} t_{i}}{\sum_{i=1}^{N} \mu_{i}}
\end{array}
$$

\section{Algorithm for tracing the unreliability of shipboard distribution system}

The algorithm to find the weak parts of the shipboard distribution system are shown as follows:

Step1: read the system data and compute the trend of normal state;

Step2: enumerate fault events, obtain system state;

Step3: calculate the reliability indices of above system state;

Step4: based on reliability tracing principles, the reliability index can be distributed to individual failed components. Calculate reliability tracing index of every component.

Step5: judge whether the enumeration of fault state is end, if not, turn to step2;

Step6: sort the reliability tracing index, find the weak parts of the shipboard distribution systems.

\section{Analysis of simulation result}

A computer program coded in matlab7.1 has been developed based on proposed algorithm. The ring shaped shipboard distribution system shown in Figure 1 is used to demonstrate the effectiveness of the proposed method for tracing the LOLP index. The results for the ring shaped shipboard distribution system are shown in Table 2.

Tab.2. the results of LOLP index for ring shaped shipboard distribution system

\begin{tabular}{|c|c|c|c|c|c|}
\hline No. & $L O L P_{i}$ & $L O L P \%$ & No. & $L O L P_{i}$ & $L O L P \%$ \\
\hline$b 1$ & 0.0071 & 7.085 & $c 2$ & 0.0035 & 3.483 \\
\hline$b 2$ & 0.0071 & 7.085 & $c 3$ & 0.0035 & 3.483 \\
\hline$b 3$ & 0.0071 & 7.085 & $c 4$ & 0.0035 & 3.483 \\
\hline$b 4$ & 0.0071 & 7.085 & $c 5$ & 0.0034 & 3.376 \\
\hline$b 5$ & 0.0016 & 1.613 & $c 6$ & 0.0034 & 3.376 \\
\hline$b 6$ & 0.0016 & 1.613 & $c 7$ & 0.0037 & 3.724 \\
\hline$b 7$ & 0.0016 & 1.613 & $c 8$ & 0.0037 & 3.724 \\
\hline$b 8$ & 0.0016 & 1.613 & $c 9$ & 0.0064 & 6.412 \\
\hline$b 9$ & 0.0017 & 1.702 & $c 10$ & 0.0064 & 6.412 \\
\hline$b 10$ & 0.0017 & 1.702 & $c 11$ & 0.0064 & 6.412 \\
\hline$b 11$ & 0.0017 & 1.702 & $c 12$ & 0.0064 & 6.412 \\
\hline$b 12$ & 0.0017 & 1.702 & $c 13$ & 0.0023 & 2.303 \\
\hline$c 1$ & 0.0035 & 3.483 & $c 14$ & 0.0023 & 2.303 \\
\hline
\end{tabular}

It can be seen that the same generating units installed at the same bus, such as $b 1-b 4$, have a 
same unreliability tracing results. This is because they have the same locations, reliability, and electric parameters. So they have the same contributions to the system unreliability.

The results also show that the greatest impact on the system reliability index LOLP consists of $b 1-b 4$ and $c 9-c 12$. Therefore, they are the weak parts of the ring shaped shipboard distribution system.

\section{Conclusion}

This paper focuses on the reliability analysis of shipboard power system. The MCS method is a useful approach for evaluating the reliability of a complex network. The PSP and the algorithms for tracing the unreliability are proposed in this paper. The proposed technique provides a new idea for evaluating the impact of components on the shipboard power system unreliability. The UT results can be used to recognize the weak parts of the shipboard power system, and provide useful information for improving the system reliability performance. In addition, the proposed UT technique can be easily implemented on the existing reliability evaluation programs, and conveniently expanded to other types of shipboard power system.

\section{Acknowledgement}

In this paper, the research was sponsored by the Nature Science Foundation of China (Project No. 51377167,61402516) and Youth Nature Science Foundation of Naval University of Engineering (Project No. HGDQNSQJJ15002).

\section{References}

[1] Billinton R. Composite system reliability evaluation[J].IEEE Transactions on Power Apparatus and Systems, 1969,88(4):276-281.

[2] Billinton R. Reliability assessment of electric power systems using Monte Carlo methods[M]. New York and London: Plenum Press, 1994.

[3] Billinton R. Evaluation power reliability of power System[M].2nd ed. New York and London: Plenum Press, 1996.

[4] LI W Y. Risk assessment of power systems: models, methods, and applications[M].New York: IEEE Press/Wiley,2005.

[5] Billinton R, Huang D. Effects of load forecast uncertainty on bulk electric system reliability evaluation[J]. IEEE Transactions on Power Systems 2008,23(2):418-425.

[6] Moghadasi S M, Kazemi A, Fotuhi-Firuzabad M, Edris A A. Composite system reliability assessment incorporating an interline power-flow controller[J]. IEEE Transactions on Power Delivery 2008,23(2):1191-1199.

[7] Leite da Silva AM, Resende LC, Manso LAF, Miranda V, Composite reliability assessment based on Monte Carlo simulation and artificial neural networks[J]. IEEE Transactions on Power Systems, 2007,22(3):1202-1209.

[8] Bhuiyan MR, Allan RN. Inclusion of weather effects in composite system reliability evaluation using sequential simulation[J]. IEEE Proceedings Generation, Transmission and Distribution, 1994, 141(6):575-584.

[9] Billinton R, Nighot R. Incorporating station-related outages in composite system reliability analysis[J]. IEEE Proceedings Generation, Transmission and Distribution 2005,152(2):227-232.

[10] Xie K, Zhou J, Billinton R. Tracing the unreliability contributions of power system components[J]. Electric Power Components and Systems, 2008,36(12):1299-1309.

[11] Xie K, Billinton R. Tracing the unreliability and recognizing the major unreliability contribution of network components[J]. Reliability Engineering and System Safty, 2009,94(5): 927-931. 